\title{
Multimodal approaches and tailored therapies for pain management: the trolley analgesic model
}

This article was published in the following Dove Medical Press journal: Journal of Pain Research

\author{
Arturo Cuomol,* \\ Sabrina Bimonte ${ }^{1, *}$ \\ Cira Antonietta Forte' \\ Gerardo Botti \\ Marco Cascella' \\ 'Division of Anesthesia and Pain \\ Medicine, Istituto Nazionale Tumori, \\ IRCCS - Fondazione G Pascale, \\ Naples, Italy; ${ }^{2}$ Scientific Direction, \\ Istituto Nazionale Tumori, IRCCS - \\ Fondazione G Pascale, Naples, Italy \\ *These authors contributed equally to \\ this work
}

Correspondence: Sabrina Bimonte Division of Anesthesia and Pain Medicine, Istituto Nazionale Tumori, IRCCS Fondazione G Pascale, Via Mariano Semmola, 52, 80I3I Naples, Italy Email s.bimonte@istitutotumori.na.it

\begin{abstract}
Chronic pain is described as a manifestation of real or potential tissue damage. It is identified as a perception influenced by the complex interactions of biological, psychological, and social factors. Different types of pain and their comorbidities dramatically affect patients' quality of life and their families. Due to diverse etiology and pathogenesis, pain management represents a controversial issue in clinical practice. In 1986, the WHO developed a three-step ladder model based on the use of analgesics for pain management according to pain intensity in a linear up or down movement. Despite its huge value for pain relief, this model has some limitations, and some controversies in the pharmacotherapy of pain management have arisen so far. To bypass these difficulties, the concept of WHO analgesic ladder has been contested and changed into a four bidirectional step model which postulates the use of the invasive procedures (neuromodulatory and neurosurgical procedures). Moreover, with the introduction of the neuromatrix theory for dealing the acute and the chronic pain, the WHO model was newly reinterpreted and changed into a platform analgesic model that includes multimodal pharmacological and alternative treatments applicable to all pain conditions, although excludes the precision therapies. Here, we summarize and revise these concepts in order to propose a new model termed "trolley analgesic model" that will allow adopting tailored therapies with dynamic multimodal approaches for pain management according to 1) the pain intensity, 2) the physiopathology of pain, 3) the complexity of symptoms, 4) the presence of comorbidity, and 5) the physiopathological factors and the social context.
\end{abstract}

Keywords: cancer and no-cancer pain management, personalized treatment, analgesic trolley, multimodal approaches

\section{The original WHO analgesic ladder and its modifications}

In 1986, the WHO published a revolutionary model on the use of analgesics in pain treatment, named the WHO analgesic ladder, ${ }^{1,2}$ subsequently updated a decade later. ${ }^{3}$ This simple approach was firstly developed for cancer pain relief with a succession rate of $80 \%-90 \%,{ }^{4}$ and then was extended to the majority of pain conditions. ${ }^{5}$ The concept of ladder was developed on a three-step approach of sequential use - from no-treatment to strong opioids - of agents, given preferentially orally, at regular intervals and without a prefixed dosage. The pharmacological approach - in terms of drugs and doses - is based on the pain intensity reported by patients. Thus, in the first step, treatment begins with nonsteroidal anti-inflammatory drugs (NSAIDs) 
and other non-opioids (eg, acetaminophen) for mild pain. If the pain persists and thus is classified as moderate pain, therapy with mild opioids (eg, codeine, tramadol, alone or combined with tramadol) is started, and in some cases, associated with strong opioids at lower doses. Finally, the third step in the treatment of severe and persistent pain of advanced disease is the use of strong opioids (eg, morphine, buprenorphine fentanyl, oxycodone, hydromorphone, and tapentadol), in combination or not with non-opioids. ${ }^{6-9}$ Pharmacological adjuvant treatment can be associated with opioids and no-opioids in each step of the ladder, in order to obtain pain relief. ${ }^{10}$

Although the feasibility and the efficacy of the original WHO ladder has been proven by several clinical experiences, ${ }^{11-13}$ some methodologic limitations on its use (eg, small sample size, inadequate follow-up) have arisen until now, in addition to several side effects associated with nonopioids and opioids agents. For instance, the long-term use of NSAIDs combined with opioids for treating moderate pain can lead to heartburn, and renal and gastrointestinal dysfunctions. ${ }^{14}$ Moreover, the use of mild and strong opioids (considered effective pain relievers), leads to constipation, drowsiness, and nausea. ${ }^{15,16}$ Apart from these side effects, several clinical trials on the use of mild opioids for the control of chronic pain showed a lack of efficacy in comparison with strong opioids treatment; ${ }^{17,18}$ thus, some clinicians suggested the elimination of the second step.

Regarding the quality of life, some authors have devised an adaptation of the WHO analgesic ladder, which introduces the fourth step. This latter step includes interventional approaches such as neurosurgical procedures (eg, neuromodulation, nerve blocks, brain stimulators, and nerve lysis) strongly suggested for the control of persistent pain (prevalently of neuropathic onset) even after treatment with strong opioids. Moreover, this modified ladder can be used in a bidirectional manner on the basis of type of pain and its intensity. ${ }^{2,19-23}$

\section{Multimodal approaches for personalized pain treatment: the analgesic trolley model}

Over the past years, the concept of neuromatrix has evolved and led to the establishment of a new concept of pain, which is not more viewed as a linear experience directly induced by sensory input evoked by inflammation or other diseases, but as a multidimensional experience evoked by a neural network widely distributed in the brain. ${ }^{24,25}$ Based on this point of view, Leung tentatively modified the original analgesic WHO ladder into a new analgesic model represented as a platform. In this model, pain management followed a three-dimensional perspective including different domains that, in a multimodal manner, can be added to classical analgesics, on the basis of the pain condition. ${ }^{26}$

Despite the innovation of the platform model due to the introduction of the concept regarding the multimodal approaches applied to pain management, this model seems to be lacking in completeness. A serious platform limitation is that this strategy does not include in the domains the precision therapies that need to be considered in order to elaborate a personalized therapy.

Clinical shreds of evidence lead us to assert that pain can be considered as "biopsychosocial perception" since it mimics a unique individual patient experience with multifactorial genesis. Moreover, it represents a dynamic experience, highly variable in a spatial-temporal manner; thus, it is not imaginable to assume its therapy as universally applicable.

Thus, it is necessary to re-think the concept of pain management. Pain treatments need to follow multimodal approaches (pharmacological and nonpharmacological agents according to principle of international guidelines on the management of chronic pain) considering 1) the intensity of pain, 2) the pathophysiology of pain, 3) the complexity of symptoms, 4) the presence of comorbidity, 5) the social context, and 6) the "time" of illness. On these promises, we propose a simple and an intuitive model for pain relief, termed "the analgesic trolley" (Figure 1).

In this model, the pharmacological agents and the nonpharmacological methods foreseen and coded in the pain therapy are contained in special drawers. Each drawer of the trolley identifies a category of drugs or an operative technique (eg, neurolysis) or noninvasive (eg, psychotherapy and yoga) therapy. It will be entrusted to the competence of each clinician to draw on one or more drawers, and to choose in the drawers the most appropriate therapeutic modality, remaining ready to close a drawer, open another, and to modify the choices on the basis of therapeutic needs at the time of presenting patient pain.

The application of this dynamic model (metaphorically represented by the wheels of the trolley as showed in Figure 1) in clinical practice will allow to manage pain in a holistic manner and to provide personalized therapy for patients suffering from pain. 


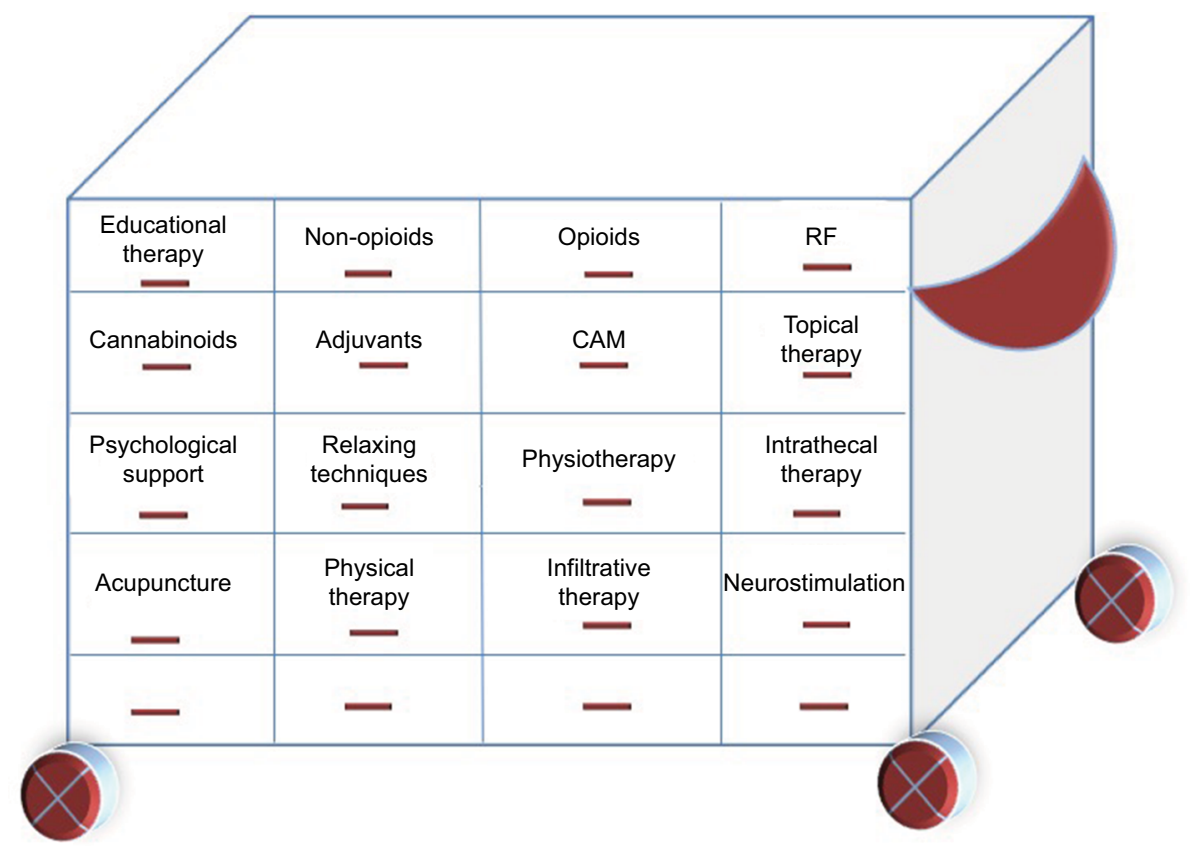

Figure I The analgesic trolley model for pain management.

Abbreviations: CAM, complementary and alternative medicine; RF, radiofrequency.

\section{Disclosure}

The authors report no conflicts of interest in this work.

\section{References}

1. Ventafridda V, Saita L, Ripamonti C, De Conno F. WHO guidelines for the use of analgesics in cancer pain. Int J Tissue React. 1985;7(1):93-96.

2. Vargas-Schaffer G. Is the WHO analgesic ladder still valid? Twenty-four years of experience. Can Fam Physician. 2010;56(6):514-517.

3. Stjernswärd J, Colleau SM, Ventafridda V. The World Health Organization cancer pain and palliative care program past, present, and future. J Pain Symptom Manage. 1996;12(2):65-72.

4. Stjernsward J. WHO cancer pain relief programme. Cancer Surv. 1988;7(1):195-208.

5. Portenoy RK. Treatment of cancer pain. The Lancet. 2011;377(9784): 2236-2247.

6. Mercadante S. Management of cancer pain. Intern Emerg Med. 2010; 5(S1):31-35.

7. Grond S, Radbruch L, Meuser T, Loick G, Sabatowski R, Lehmann KA. High-dose tramadol in comparison to low-dose morphine for cancer pain relief. J Pain Symptom Manage. 1999;18(3):174-179.

8. Mercadante S, Salvaggio L, Dardanoni G, Agnello A, Garofalo S. Dextropropoxyphene versus morphine in opioid-naive cancer patients with pain. J Pain Symptom Manage. 1998;15(2):76-81.

9. Marinangeli F, Ciccozzi A, Leonardis M, et al. Use of strong opioids in advanced cancer pain: a randomized trial. J Pain Symptom Manage. 2004;27(5):409-416.

10. Lui F, Ng KF. Adjuvant analgesics in acute pain. Expert Opin Pharmacother. 2011;12(3):363-385.

11. Ventafridda V, Tamburini M, Caraceni A, De Conno F, Naldi F. A validation study of the WHO method for cancer pain relief. Cancer. 1987;59(4):850-856.

12. Walker VA, Hoskin PJ, Hanks GW, White ID. Evaluation of WHO analgesic guidelines for cancer pain in a hospital-based palliative care unit. J Pain Symptom Manage. 1988;3(3):145-149.

13. Meuser T, Pietruck C, Radbruch L, Stute P, Lehmann KA, Grond S. Symptoms during cancer pain treatment following WHO-guidelines: a longitudinal follow-up study of symptom prevalence, severity and etiology. Pain. 2001;93(3):247-257.
14. Nikose S, Arora M. Gastrointestinal adverse effects due to use of nonsteroidal anti-inflammatory drugs (NSAIDs) in non-traumatic painful musculoskeletal disorders. J Gastrointest Dig Syst. 2015;05(06):348.

15. Sinatra R. Causes and consequences of inadequate management of acute pain. Pain Med. 2010;11(12):1859-1871.

16. Porreca F, Ossipov MH. Nausea and vomiting side effects with opioid analgesics during treatment of chronic pain: mechanisms, implications, and management options. Pain Med. 2009;10(4):654-662.

17. Schug SA, Auret K. Clinical pharmacology: principles of analgesic drug management. Sykes. 2008:103-122.

18. Vielvoye-Kerkmeer AP, Mattern C, Uitendaal MP. Transdermal fentanyl in opioid-naive cancer pain patients: an open trial using transdermal fentanyl for the treatment of chronic cancer pain in opioid-naive patients and a group using codeine. J Pain Symptom Manage. 2000;19(3):185-192.

19. Jadad AR, Browman GP. The WHO analgesic ladder for cancer pain management. Stepping up the quality of its evaluation. JAMA. 1995;274(23):1870-1873.

20. Dworkin RH, O'Connor AB, Backonja M, et al. Pharmacologic management of neuropathic pain: evidence-based recommendations. Pain. 2007;132(3):237-251.

21. Cascella M, Cuomo A, Viscardi D. Psychological, behavioral, and rehabilitation approaches to cancer pain management. In: Features and Management of the Pelvic Cancer Pain. New York: Springer; 2016:143-149.

22. Sommer C. Exploring pain pathophysiology in patients. Science. 2016;354(6312):588-592.

23. Bimonte S, Cascella M, Schiavone V, Mehrabi-Kermani F, Cuomo A. The roles of epigallocatechin-3-gallate in the treatment of neuropathic pain: an update on preclinical in vivo studies and future perspectives. Drug Des Devel Ther. 2017;11:2737-2742.

24. Melzack R. Pain and the neuromatrix in the brain. J Dent Educ. 2001;65(12):1378-1382.

25. Melzack R. Evolution of the neuromatrix theory of pain. The Prithvi Raj Lecture: presented at the Third World Congress of World Institute of Pain, Barcelona 2004. Pain Pract. 2005;5(2):85-94.

26. Leung L. From ladder to platform: a new concept for pain management. J Prim Health Care. 2012;4(3):254-258. 
The Journal of Pain Research is an international, peer reviewed, open access, online journal that welcomes laboratory and clinical findings in the fields of pain research and the prevention and management of pain. Original research, reviews, symposium reports, hypothesis formation and commentaries are all considered for publication.
Dovepress

The manuscript management system is completely online and includes a very quick and fair peer-review system, which is all easy to use. Visit http://www.dovepress.com/testimonials.php to read real quotes from published authors. 